\title{
Transport in Developing Countries: Renewable Energy versus Energy Reduction?
}

\author{
DIRK AßMANN* and NIKLAS SIEBER** \\ *Environment and Infrastructure Division, German Technical Co-operation (GTZ), Eschborn, \\ Germany **Freelance Transport Expert, Stuttgart, Germany
}

(Received 28 July 2004; revised 3 June 2005; accepted 6 June 2005)

\begin{abstract}
Transport consumes worldwide about one-fifth of global primary energy and is thus responsible for similar amounts of greenhouse gas emissions. In the future, it can be expected that with an increasing transport demand in the rapidly growing economies of the developing world, the problems will be even more severe. This paper gives an overview on the developments in the South and discusses options for renewable sources of energy in transportation, which are expected to be solutions for oil shortages and greenhouse effects. However, the analysis shows that with a few exceptions in the near future, most of the proposed energy sources are not viable in economic and technical terms. Rising fuel prices will make biofuels competitive and provide opportunities for developing countries. Nevertheless, 'traditional' transport approaches, such as inspection and maintenance or rapid bus services can have strong impacts in developing countries.
\end{abstract}

\section{Introduction}

Worldwide, the transport sector consumes about one-fifth of primary energy and is responsible for almost $60 \%$ of oil consumption in Organization for Economic Co-operation and Development (OECD) countries with an increasing consumption in the developing world. ${ }^{1}$ After the energy sector, transport is the most important producer of carbon dioxide $\left(\mathrm{CO}_{2}\right)$. Unlike the energy sector, energy consumption and greenhouse gas emissions of the transport sector are still increasing in many industrialized countries. The problem is even more severe in developing countries, where enormous growth is required to catch up with the industrialized world as experience shows that economic growth is strongly correlated with growth in transport volumes.

Figure 1 shows the rapid increase of worldwide motorization since 1930. Between 1980 and 1995, just 15 years, the global fleet of cars, trucks, and buses increased by $60 \%$, with one-third of the increase being in developing countries. Research by The World Bank (Ingram and Liu, 1999) has indicated that vehicle fleets grow at the pace of economic growth. Ingram and Liu estimate that the 


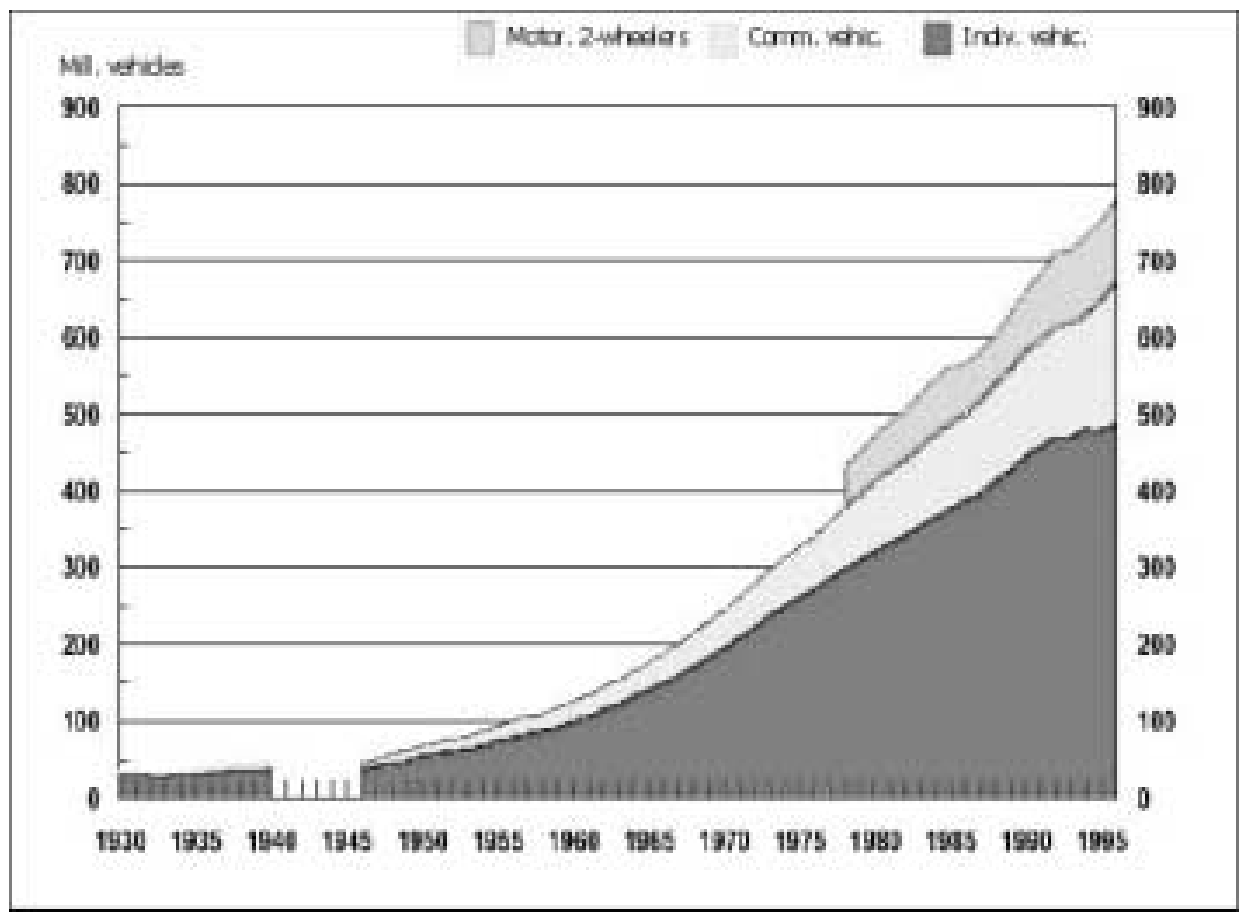

Figure 1. Motorization trend worldwide, 1930-95. Source: Bundesministerium für wirtschaftliche Zusammenarbeit und Entwicklung (2003, p. 49)

vehicle fleet will grow by seven times by 2050. Estimations are performed based on income and price elasticities of motor vehicle ownership and use. The authors also take population densities and saturation levels for motor vehicle ownership into account.

Apart from the positive development effects linked to the economic growth process, the negative impacts of transport, such as the emissions of greenhouse gases and pollutants, are well known. Development strategies face a dilemma, since growth is highly desirable, but not its negative effects. Thus, a sustainable transport strategy has to take into account the growing transport demands in developing countries and reduce emissions at the same time. The key question is as follows. What are the main pillars to a sustainable transport system? Are renewables the solution, is energy efficiency more important or does one need integrated approaches?

The heuristic (Figure 2) shows that transport emissions are dependent on transport volumes, specific fuel consumption and emissions per unit of fuel. Transport planners have various leverage points in order to change emission volumes and energy consumption. This paper will give an overview on the most relevant measures for developing countries:

- Technical options for conventional engines, such as engine technologies, vehicle characteristics, inspection and maintenance, and fuel quality.

- Options for renewable energies in transport, such as ethanol and biogas.

- Planning approaches for efficient transport systems, such as transport demand management, land-use planning and fuel pricing. 


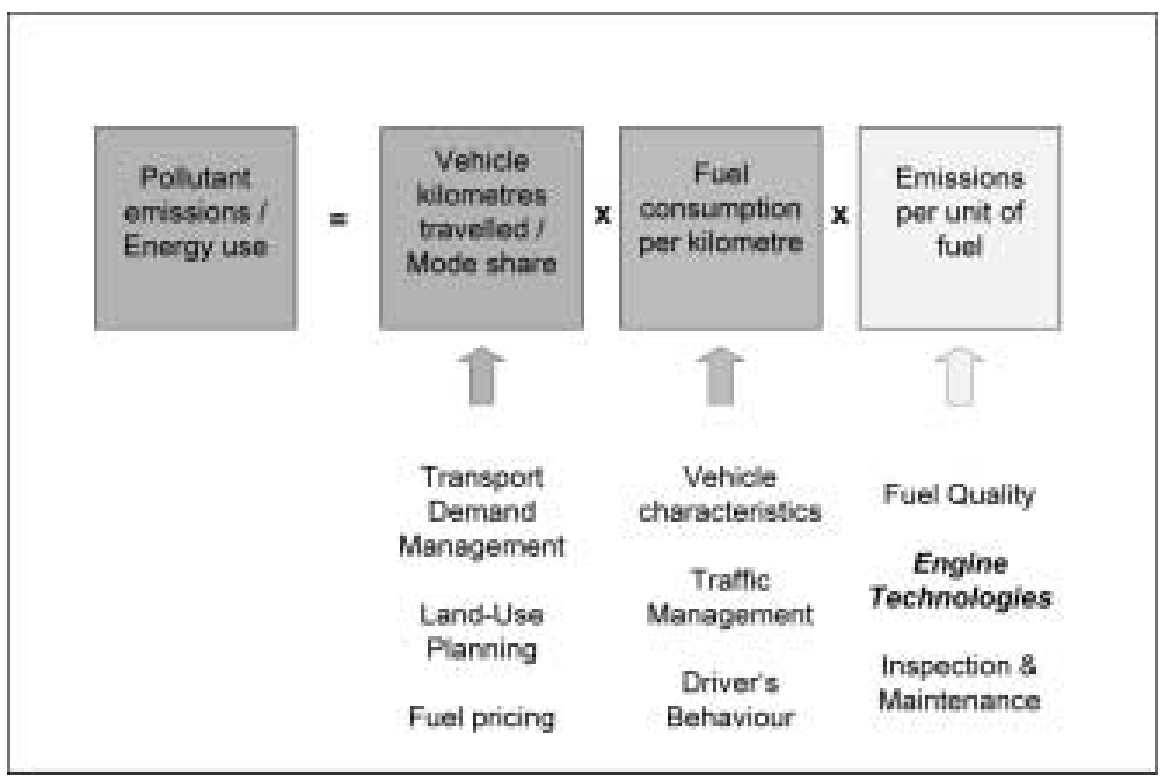

Figure 2. Energy consumption is based on many factors. Source: Wright (2004)

These options do not represent a comprehensive set, but the most prominent measures to improve transport systems in the developing world. They will be discussed with regard to their relevance for developing countries, their technical feasibility and competitiveness compared with existing solutions.

\section{Technical Options for Conventional Engines}

In industrialized countries, public pressure has resulted in an increase of the energy efficiency of engines in transport, accompanied by improved emission regulations, entailing air pollution-reduction technologies, such as three-way catalytic converters and filters. While during the last four decades emissions of pollutants have largely decreased, fuel consumption and thus greenhouse gas (GHG) emissions in transport have increased due to growing transport volumes and more powerful engines. The example of Germany (Figure 3) shows that over the last 40 years, average engine power has more than doubled. Since the 1960s, this process was accompanied by an increase of specific fuel consumption. From the 1980s onwards, a slight decline (16\%) can be observed, which was due to technical efficiency improvements and a larger share of diesel engines in the vehicle fleet. However, the efficiency improvements could not compensate entirely for increasing engine power. Thus, the low consumptions from the 1960s have not been maintained, and in North America a similar trend can be observed.

However, a significant potential for a further decrease of average fuel consumption exists in the developed world. Volkswagen has demonstrated that a car driven by a one-piston diesel engine can reduce energy consumption to less than 1 litre/ $100 \mathrm{~km}$. However, this vehicle is not available for every day use. ${ }^{2}$ In commercial markets, low consumption cars are offered that consume 3 litres diesel/100 km. ${ }^{3}$ The disadvantages of diesel engines are higher $\mathrm{CO}_{2}$ emissions/litre of fuel and the particulates when not using a filter. The best commercial petrol cars ${ }^{4}$ consume slightly less than 5 litres $/ 100 \mathrm{~km}$ and are still in a competitive price range. Hybrid 


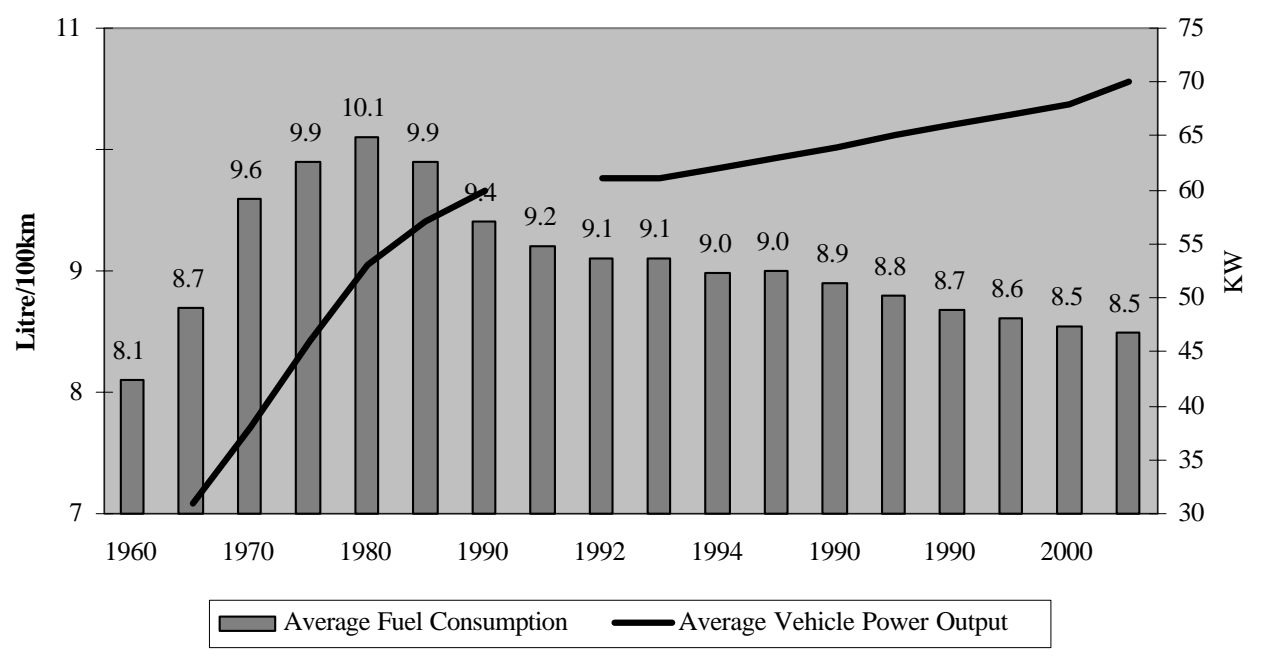

Figure 3. Fuel consumption and vehicle power of private cars in Germany. Source: Verkehr in Zahlen 2002/03

engines, combining petrol and electric engines, have an even higher energy efficiency, but they are presently much more costly. ${ }^{5}$

In most developing countries, a large share of the vehicle fleet consists of second-hand vehicles purchased from industrialized countries. It seems that the richer the country, the smaller the share of second-hand vehicles. In low-income countries, especially in Africa, used cars are very common, but in emerging economies the share of new cars is considerably higher. Therefore, in poor countries the emission levels can be compared with those of used cars in the developed world and any efficiency improvements implemented in the North will also have long run effects in the South. Thus, without additional measures, the energy efficiency of vehicles in developing countries will not be any better than it used to be 5-10 years ago in the developed world. In developing countries, fuel prices are often fairly low (see below), and low-consumption vehicles comprise only a small market share, which is balanced by the large number of off-road vehicles, which are badly needed on poor roads.

A significant decrease of pollutant emissions can be achieved in developing countries, if European emission standards such as Euro II-IV are implemented. Many countries have already introduced Euro I Standard, some Euro II and a few even Euro III. ${ }^{6}$ Preconditions are the introduction of legal binding requirements for mandatory roadworthiness tests, combined with a set of regulations, dealing with fines and other sanctions. However, this requires a dedicated government that is willing undertake a considerable effort in order to implement this comprehensive set of measures. A first step towards the necessary higher environmental standards is an improvement in the fuel quality, e.g. by reducing the sulphur content in both petrol and diesel.

Anybody travelling in developing countries can easily observe that black smoke is often produced by vehicles. Emission standards are simply not met because engines are badly adjusted and vehicles poorly maintained. The reason is a missing or insufficient system of inspection and maintenance, which can reduce fuel consumption by $3-7 \%$ and, hence, leads to a similar decrease in $\mathrm{CO}_{2}$ 
emissions. ${ }^{7}$ This is especially true for two- and three-wheelers, which emerge as a major problem in many Asian towns. In Delhi, India, two- and three-wheelers produce three-quarters of the particulates and roughly one-third of the hydrocarbon (HC) emissions. ${ }^{8}$ Especially for two-stroke engines, the pollution problem is often visible. Since the vehicles are relatively cheap, reliable and easy to repair, they are a very popular mode of transport for the poor. Because replacement by cleaner technologies in the short run is not feasible, inspection and maintenance and tighter emission standards are the only measures to limit the negative effects.

\section{Conclusion}

Second-hand cars used in the North dominate the vehicle fleet in the South. In the long run, technological improvements will also have an impact in the South. Effective environmental improvements can be achieved by introducing European standards, which implies a strong political will from government. A first step towards cleaner transport could be an improvement in fuel quality, e.g. by reducing the sulphur content of both petrol and diesel. However, without an extensive system of inspection and maintenance, these improvements will simply evaporate.

\section{Options for Renewable Energies in Transport}

\section{Which Energy is Renewable?}

Renewable energies can be used in various forms and in different sectors for different purposes. Since renewable energies are not really renewable, a short introduction will be given.

Solar energy manifests itself as low-temperature solar heat, high-temperature solar heat, wind electricity and photovoltaics. Low-temperature solar heat is produced by the absorption of sunlight by darkened surfaces. The heat can be used to provide warm water or other fluids. High-temperature solar heat can be obtained by focusing sunlight in order to produce high temperatures in so-called heating fluids, which can be used to generate electricity or provide industrial processes. Wind electricity is generated by airflows, caused by the warming of the atmosphere due to solar radiation. Photovoltaics result from the direct conversion of the ultraviolet component of sunlight into electricity in appropriate surfaces. These forms of energy are all renewable by definition.

Geothermal energy, in the form of hot water or vapour, can be used for heat or electricity production in some geological-specific regions. It is a renewable energy source if its use is equal to or less than the heat production (caused by nuclear fission processes) inside the planet. Tidal energy can be used to generate electricity in some coastal areas and is also a renewable source of energy.

Hydropower is indirectly linked to sunlight, since it evaporates water from the oceans, which in turn precipitates in the form of rain, forming rivers on the continents. Dams are built on rivers forming reservoirs, which guarantee a steady supply of water for the generation of electricity. Major hydropower plants flooding large areas might displace people and entail undesirable ecological or social impacts. Therefore, some people consider them not as a renewable energy source, although physically this is not correct. Small hydropower plants are usually not affected by such problems. However, this example shows that the term 'renewable' does not automatically mean socially or environmentally friendly. 
A small part of the solar energy reaching the Earth is converted by photosynthesis into biomass (organic matter). Part of such matter was buried hundreds of millions of years ago by sediments and earthquakes and transformed by bacterial action and natural processes such as heat and pressure into coal, oil and gas, which presently constitute the non-renewable fossil fuel resources. Biomass is usually classified as a renewable energy, except when leading to deforestation or erosion. It can be used in two ways:

- Traditional or non-commercial biomass, such as crop residues, fuel-wood and animal dung, is frequently used with very low efficiencies for cooking and heating in many developing countries. Although these unprocessed fuels can be used renewed, they frequently increase deforestation and erosion. Therefore, programmes to develop and disseminate improved biomass stoves in many African countries, China and India are of major importance.

- Modern biomass is that produced sustainably and used for the generation of electricity, heat production and transportation (liquid fuels). It includes wood and forest residues from reforestation or sustainable forest management, energy crops from organic production, and rural and urban residues such as solid waste and liquid effluents.

The most important energy source is only renewable if replacement becomes a reality. Sometimes, biomass used in developing countries, either on a small scale for domestic use or on a large scale for industrial purposes, leads to deforestation. Degradation of primary forests or inappropriate reforestation, e.g. using eucalyptus, needs to be avoided. Moreover, biomass used for cooking and heating is a major cause of serious indoor pollution, particularly to women, small children and the elderly.

Until industrialization in the 18th and 19th centuries, energy supply was mainly based on renewable energies, especially biomass and hydro. Rising demand and new technologies led to better living and working conditions, but also to a harmful change in the energy supply concerning ecological issues. Today, there are important differences in the energy systems of OECD and developing countries (Table 1). In OECD countries, which have reached a very high level of development, gains in energy efficiency have been the main strategy used to decrease energy consumption. In developing countries where renewables (mainly biomass) are already very important - albeit used in inefficient ways modernization of their usage seems the better strategy to follow.

As Figure 4 shows, around $14 \%$ of the total world energy consumption ${ }^{9}$ is provided by renewable energies. Apart from biomass (meaning here combustible renewables and waste), hydro has the highest share. The 'new' renewables such

Table 1. Characteristics of the global primary energy demand, 2000

\begin{tabular}{lcccc}
\hline & $\begin{array}{c}\text { Fossil fuels } \\
(\%)\end{array}$ & $\begin{array}{c}\text { Renewable } \\
\text { energy }(\%)\end{array}$ & $\begin{array}{c}\text { Nuclear } \\
(\%)\end{array}$ & $\begin{array}{c}\text { Growth rate, all sources } \\
(\% / y e a r, ~ 1971-2000)\end{array}$ \\
\hline $\begin{array}{l}\text { Organization for Economic } \\
\begin{array}{l}\text { Co-operation and } \\
\text { Development (OECD) }\end{array}\end{array}$ & 82.7 & 6.2 & 11.0 & 1.6 \\
\begin{tabular}{l} 
Developing countries \\
\hline
\end{tabular} & 71.7 & 27.6 & 0.7 & 3.9 \\
\hline
\end{tabular}

Source: IEA (2004). 


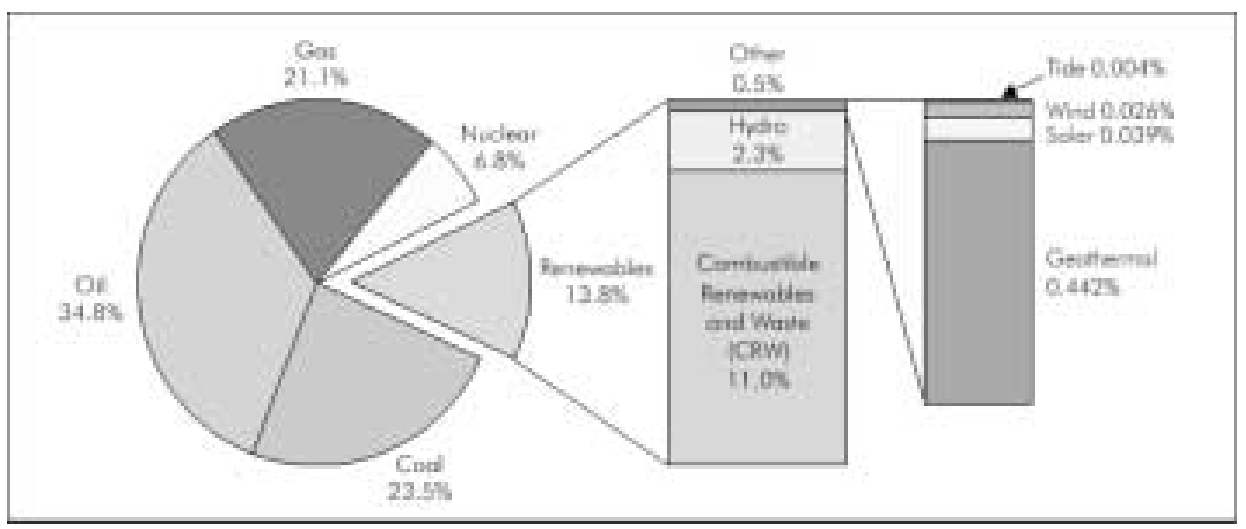

Figure 4. Global primary energy demand, 2000

as solar, wind and geothermal energy only contribute to less than $1 \%$ of global production.

\section{Potentials of Renewable Sources}

The natural energy flows through the Earth's ecosystem exceed current energy use by several times. Admittedly, an analysis based on this theoretical potential is irrelevant because hydrocarbon occurrences or natural flows become resources only if there is demand for them, and appropriate technology has been developed for their conversion and use. Therefore, the appraisal of technical potential only takes into account engineering and technological criteria (Table 2). The picture shown in Table 2 is clear: the potentials for renewable energy resources are immense and will not act as a constraint on their development.

\section{Technical Options in Transport}

In the transport sector, the following experiences have been made with renewable sources of energy: ${ }^{10}$

- Biodiesel has strong impacts on greenhouse gas mitigation, since no fossil $\mathrm{CO}_{2}$ is burned. Life-cycle analyses show that the use of biodiesel reduces net $\mathrm{CO}_{2}$ emission by more than $75 \%$ compared with petroleum diesel (Quirin et al.,

Table 2. Global renewable resource base (Exajoules per year)

\begin{tabular}{lccr}
\hline Resource & Current use & Technical potential & Theoretical potential \\
\hline Hydropower & 10.0 & 50 & 150 \\
Biomass energy & 50.0 & $>250$ & 2900 \\
Solar energy & 0.2 & $>1600$ & 3900000 \\
Wind energy & 0.2 & 600 & 6000 \\
Geothermal energy & 2.0 & 5000 & 140000000 \\
Ocean energy & - & - & 7400 \\
Total & 62.4 & $>7500$ & $>143000000$ \\
\hline
\end{tabular}

Source: Johansson et al. (2004). 
2004). This is due to biodiesel's closed carbon cycle. ${ }^{11}$ Presently, the high cost of biodiesel fuel is one of the principal barriers for its extensive usage, which could be removed by higher tax incentives. A long-term cost reduction for developing countries is not expected. Similar to conventional diesel engines, biodiesel causes particulate emissions that need to be reduced by particulate traps.

- Methanol can be produced from natural gas or from wood or cellulose. Strong impacts on GHG emissions can be expected, if it is produced from biomass, which reduces emissions by $60 \%$ compared with petrol. However, there is little prospect that methanol will become price competitive with conventional fuels in the near future.

- Ethanol is produced by the fermentation of starch from grain and thus has strong impacts on $\mathrm{CO}_{2}$ emissions. Worldwide, the largest application is the Brazilian Proálcool Programme, which initially was promoted by massive government support. Recent experience shows that although government subsidies have been cut, ethanol prices were close to competitive compared with petrol. One reason might high oil prices.

- Hydrogen as a source of transport energy can only reduce GHG emissions if it is produced using renewable resources. The total life cycle shows that using other fossil primary energy for the production of hydrogen does not result in a net $\mathrm{CO}_{2}$ advantage. Despite its promising potential as an environmental friendly source of energy in transport, the technology is presently not sufficiently developed for a widespread and cost-efficient use in developing countries.

- Fuel cells can have an impact on GHG emissions if renewable energies are used to produce the fuel. Presently, those technologies are not sufficiently developed to be used on a large scale in industrialized countries. It is not advisable to introduce technologies in the South, which have not been sufficiently tested in the North as regards their technical and economical viability.

- Electric vehicles have a strong potential impact on $\mathrm{CO}_{2}$ emissions, depending on the mode of electricity production. Countries such as Brazil, which have a large share of hydropower, are more favourable. Electric vehicles are less noisy and produce no local emissions. The disadvantage is still the limited range of the vehicle, which requires frequent refuelling. Therefore, their use makes sense in ecologically very sensitive areas and in urban areas.

- Natural gas vehicles (CNG) do not use a renewable energy, but they lead to a 15-20\% reduction of GHG emissions compared with petrol vehicles due to the $25 \%$ lower carbon content of natural gas compared with petrol. The conversion of conventional engines is possible, but this causes additional costs to the vehicle owner. No impact can be expected from the conversion of diesel-powered heavy-duty vehicles. Another problem for the user is refuelling; the storage of gas for the supplier is also a problem. Since large-scale investments are necessary to build a countrywide refuelling network, the conversion of vehicle fleets, such as taxis or buses, is recommended.

- Liquefied petroleum gas (LPG) has similar features as natural gas as regards environmental impacts, but GHG emissions are slightly higher. Since LPG is collected from oil wells, where it is usually burned, its supply is limited.

Although the effects of new energy sources in transport might be promising, their potential for actual usage in developing countries is very limited. Where natural 
gas is readily available, strong considerations should be given to replace diesel buses or taxis with CNG buses/taxis. Where natural gas or LPG is readily available, two-stroke engine autorikshaws should be considered for replacement with CNG or LPG. Economic incentives should be provided to stimulate the introduction and acceptance of the above fuels.

\section{Production and Costs of Renewables}

For the assessment of the future competitiveness of renewable energies, the price of crude oil is a crucial topic. The rapidly increasing energy demand from the growing economies in Asia has resulted in a tremendous increase of crude oil prices in the past years. First peaks were reached in November 2004 when the price per barrel reached US\$55, which compares when expressed in real terms to the second oil price shock at the beginning of the 1980s. However, in September 2005 after Hurricane Katrina, the price temporarily passed the US\$70 threshold. On 21 November, the barrel was down to US\$56. Long term forecasts to the end of the decade range between US\$42 (Merryl Lynch) and US\$60 (Goldman Sachs).

Given these price levels, renewable energies are becoming increasingly competitive. The most successful example is ethanol production in Brazil. The Proálcool Programme is worldwide the largest application, which initially was promoted by massive government support. Recent experience shows that even though government subsidies have been cut, ethanol prices were close to competing with petrol. The break-even was already reached at the beginning of the decade when oil prices began to rise while ethanol continuously became cheaper (Figure 6) due

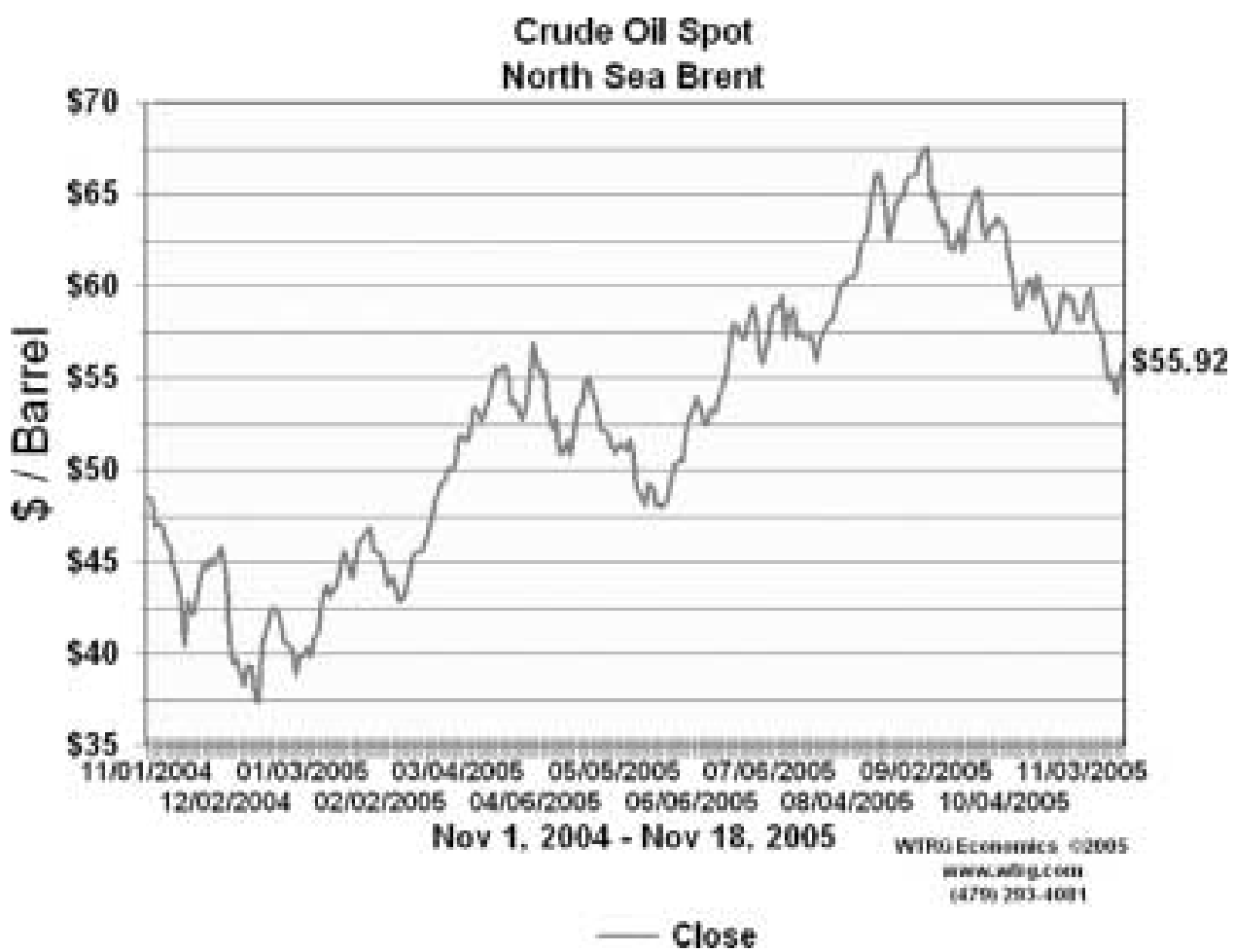

Figure 5. Crude oil prices, 2004-05. Source: WTRG (2005) 
to economies of scale entailed by increased production. Table 3 shows that in 2003 the cost of biofuel production based on sugar cane in Brazil was competitive with petrol. Given the expected oil price level of at least US $\$ 42 /$ barrel, ethanol will be economical in the long run.

The biodiesel case is different (Table 4). Under the condition of the oil price levels in 2004, biodiesel comes close to competitiveness. However, given the expected future oil price levels, biodiesel will not be competitive without certain measures, such as tax exemptions, which have been realized, e.g. in Germany.

However, note that biomass resources are limited. For example, just 5-10\% of both European diesel and petrol consumption can be provided by European biofuels. Furthermore, other processes, such as the use of hydrogen or the liquification of coal, might also become economic.

\section{Social and Ecological Aspects}

Brazil started the world's biggest biofuels programme (Proálcool) in the 1970s with research and development activities in the field of ethanol for reasons of energy security and independency. But within the last 15 years, the production and use of biofuels has been mainly discussed against the background of protecting the environment, especially climate change mitigation.

It is proven that the Brazilian ethanol programme created major social and environmental problems on the agricultural side (Weber, 2004, p. 69f). Proálcool has been criticized due to the negative environmental impacts caused by largescale monocultures. All ecological investigations show that the evaluation of biofuels depends highly on the type of agriculture used to produce the plants. The results are quite simple: the lower the use of mineral fertilisers and chemical pesticides, etc., the more appropriate the crop rotation, the more efficient the use of by-products (such as bagasse or straw in co-generation), the better the ecologi-

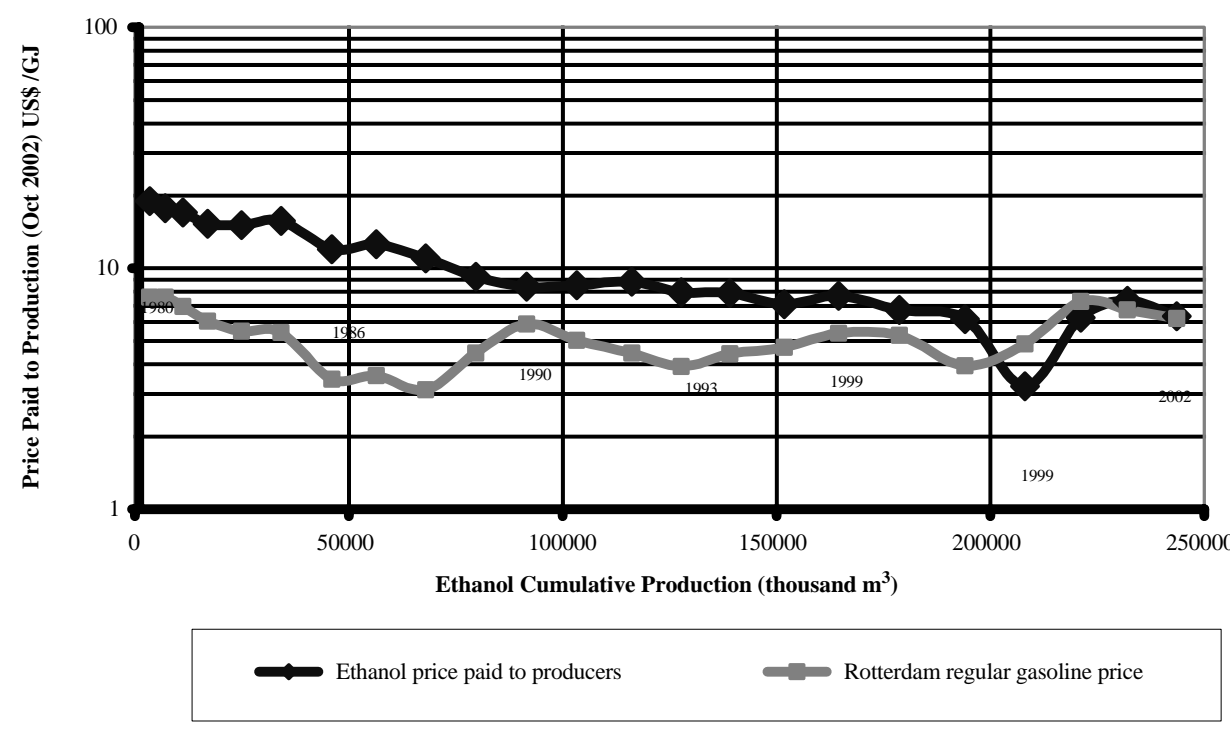

Figure 6. Price comparison of petrol in Rotterdam and ethanol in Brazil. Source: Goldemberg et al. 
Table 3. Ethanol and petrol costs before taxes, 2003

\begin{tabular}{lllc}
\hline Fuel type & Source & Country & $\begin{array}{c}\text { Production costs (US\$ } / 1 \\
\text { petrol equivalent) }\end{array}$ \\
\hline Ethanol & corn & USA & 0.43 \\
& sugar-beet & Europe & $0.63-0.90$ \\
& wheat & Europe & $0.53-0.93$ \\
Petrol & sugar cane & Brazil & $0.20-0.30$ \\
& crude oil & & $0.26-0.28$ \\
\hline
\end{tabular}

Note: The volumetric energy content of ethanol is one-third less than in the case of petrol. To compare, the costs per litre are therefore transferred into petrol equivalents.

cal evaluation. Therefore, to achieve a sound environmental production, environmental standards, and criteria through the whole production and consumption chain need to be developed and implemented.

In the last 5-7 years, a social component has been added to the discussion. The discussion focused on the question whether farmers could be the 'oil sheikhs of tomorrow'. Similar to the ecological evaluation, social impact assessment did not lead to a clear and distinct result in Brazil. The argument of farmers becoming 'oil sheikhs' is, in general, a myth. The overwhelming majority of ethanol producers are not small-scale farmers but agro-industrials and the salaries of farm workers are extremely low, whereas producers of biodiesel in Europe are 'normal' farmers. However, here the market is not yet developed enough to undertake a social impact assessment. Some experiences in the field of solid biomass, e.g. in power plants, show that big players such as energy utilities try to use their power to receive extra profits from paying extremely low prices to the farmers.

In this regard, the Malaysian case is quite interesting, as the production of plant oil does not lead to poverty reduction automatically. Malaysia is the world's biggest producer of palm oil, with agriculture having a share of $11 \%$ in the economy, and palm oil contributes $70 \%$ to it. However, to become such a big player, Malaysia destroyed large parts of its primary rainforest and thus minimized the living space for certain species, especially tigers and orang-utans. At the same time, the average salary per month (US\$92 in 2003) of the farm workers is $80 \%$ below the poverty level, and has increased by only US $\$ 1$ within the last 45 years.

On the other hand, the German Technical Co-operation (GTZ) has started a public-private partnership project on biofuels in India that might lead to an increase of farmer's income by a factor of 3-4 within a few years - while protecting the environment and generating new business opportunities.

Table 4. Biodiesel and diesel costs before taxes, 2003

\begin{tabular}{lllc}
\hline Fuel type & Source & Country & $\begin{array}{c}\text { Production costs (US\$/1 } \\
\text { diesel equivalent) }\end{array}$ \\
\hline Biodiesel & rape seed & Europe & $0.35-0.80$ \\
& soy beans & USA & $0.48-0.73$ \\
Diesel & crude oil & & $0.20-0.24$
\end{tabular}

Note: The volumetric energy content of biodiesel is a few per cent less than in the case of diesel. To compare, the costs per litre are therefore transferred into diesel equivalents. 


\section{Conclusion}

At present, regenerative sources of energy used in transport, such as biodiesel and methanol and, in most cases, ethanol, are not cost competitive compared with conventional fuels. Other technologies, such as fuel cells and hydrogen engines, are not sufficiently developed and are not yet ripe for competition in the market. They cannot be recommended for the developing world on a short-term basis until further testing and development have been made in the industrialized countries, and the economic competitiveness with conventional fuels has been proved. In some cases, such as Brazil, where the Proálcool Programme is competitive without government subsidies, investments in renewable transport options can be recommended. However, the potential for the future use of renewable energies is much higher, especially if the price of crude oil persists at the present level due to increasing demands from the developing world.

Biofuels do not contribute to poverty reduction and climate change mitigation automatically. However, considering appropriate social and ecological standards and criteria, the use of biofuels may have positive impacts on environmental protection, economic dependencies and poverty. The challenge is to combine business opportunities with these standards and to develop business models, as GTZ is trying to realize in India.

\section{Planning Approaches for Efficient Transport Systems}

Since technical improvements and the use of renewable energies in transport are limited in developing countries, planning approaches are needed to reduce energy in order to meet both the increasing transport demand and greenhouse gas reduction targets. Similar to planners in the developed world, transport planners in developing countries have a large variety of transportation demand management options. Since transportation demand management had been already discussed in depth in the transport literature (Newman and Kennworthy, 1999; McClintock, 2001), this section will highlight how transport planning has to be adapted to the needs of developing countries. But what makes the difference between planning in the North and the South?:

- High demand for a low-cost means of public transport.

- Abundance of non-motorized transport.

- High-density urban settlements with an expected future urban sprawl.

- Severe financial constraints on public budgets.

\section{Planning Low-cost Public Transport Systems}

Individual means of transport have a higher energy consumption per person transported compared with public and non-motorized modes of transport. In general, passengers driving in cars in industrialized countries consume roughly three to five times more energy than passengers transported by public modes of transport. ${ }^{12}$ Thus, energy efficiency in transport can be increased tremendously by shifting passengers from individual to public and non-motorized means of transport. Transportation demand management encompasses many measures, ranging from traffic calming, alternative work schedules, encouragement of walking and cycling, road pricing to the improvement of mass transport systems, etc. 
Most important for transportation demand management is the choice of the system for mass transportation, since large-scale investments are related to its implementation. The experience in industrialized countries shows that often mass rapid transit systems, such as metros, commuter rails or light rail transit, are not economically viable. Practically no European mass transit system operates without large-scale subsidies. Investment costs are extremely high if subterranean metro lines are to be constructed (Table 5).

In developing countries, the problems are more acute, since public funds are even scarcer than in industrialized economies. This is appropriate, since low-cost solutions have been developed in Latin America using high-quality buses for public urban transport. A very efficient Bus Rapid Transit system has been developed with the following features (Wright, 2004, p. 31):

- Segregated bus ways with transit prioritization at intersections.

- Rapid boarding and alighting using pre-paid tickets.

- Clean, secure and comfortable stations with real-time information displays.

- Modal integration of railways and non-motorized means of transport at the bus stations and terminals.

- 'Soft' characteristics, such as marketing identity (brand) or advanced customer service.

A comparison with conventional mass rapid transit systems (Table 5) shows that Bus Rapid Transit can achieve comparable results with rail systems regarding carrying capacity and service, while average speed is slower, mainly due to the lack of grade separation and the lower maximum speed achieved on the busways The main advantage is a significantly lower capital cost, especially when compared with subterranean metro systems. The main disadvantage is the large surface areas required by the buses, especially in the case of four-lane operations (Wright and Fulton, present issue ${ }^{13}$ ).

\section{Planning for Non-motorized Transport}

Walking is the dominant mode of transport for the poor. The poorer the country, the remoter the region and the smaller the integration into markets all mean that the non-motorized means of transport dominate the picture even more. Although walking consumes less energy, it is not the most efficient means of transport (Figure $7)$. Figure 7 lists typical costs in Africa for goods transported a medium distance $(50 \mathrm{~km})$ on a good road and a short distance $(5 \mathrm{~km})$ on a poor road. The most expensive mode of transport is walking. ${ }^{14}$ But the good news is that tremendous efficiency improvements can be made by using other low-cost means of transport, such as bicycles and animal carts.

The example of Bangladesh shows how efficient non-motorized means of transport can operate. A bicycle van has basically the same design as a rickshaw, only the back (load area) is designed to carry goods. Using this vehicle, a person can transport up to 1 metric ton on a flat terrain without the aid of an engine. Most bulky goods are transported by rickshaw vans, not only goods to and from markets, but also raw materials and products for small-scale industries. The abundance of rickshaw vans in Bangladeshi towns shows the economic importance of this mode for the local economy. 


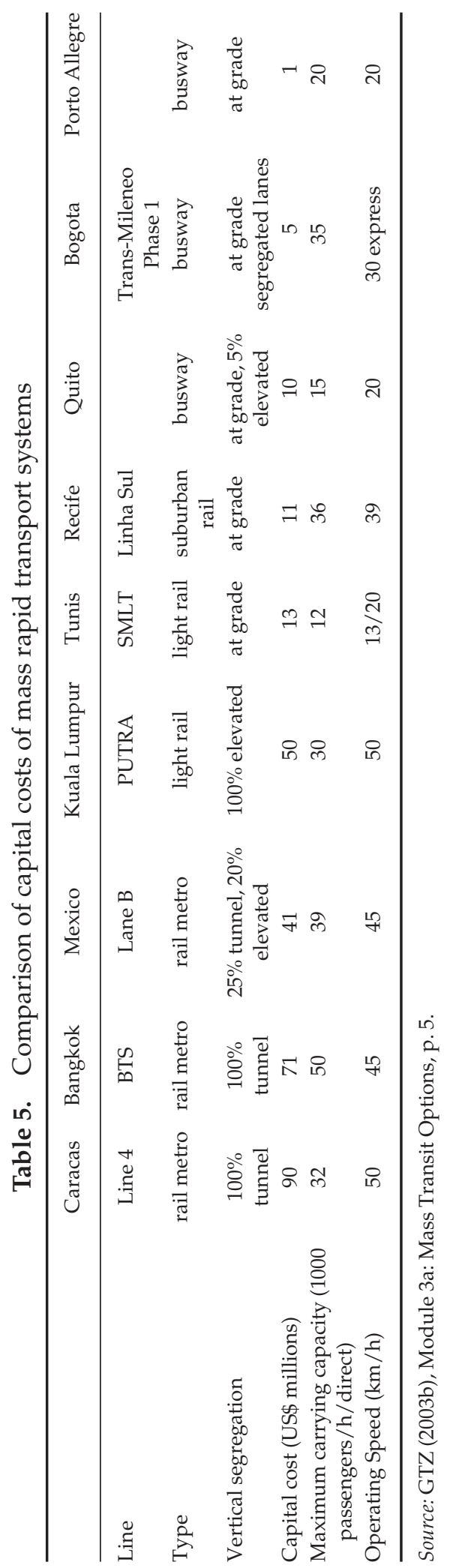




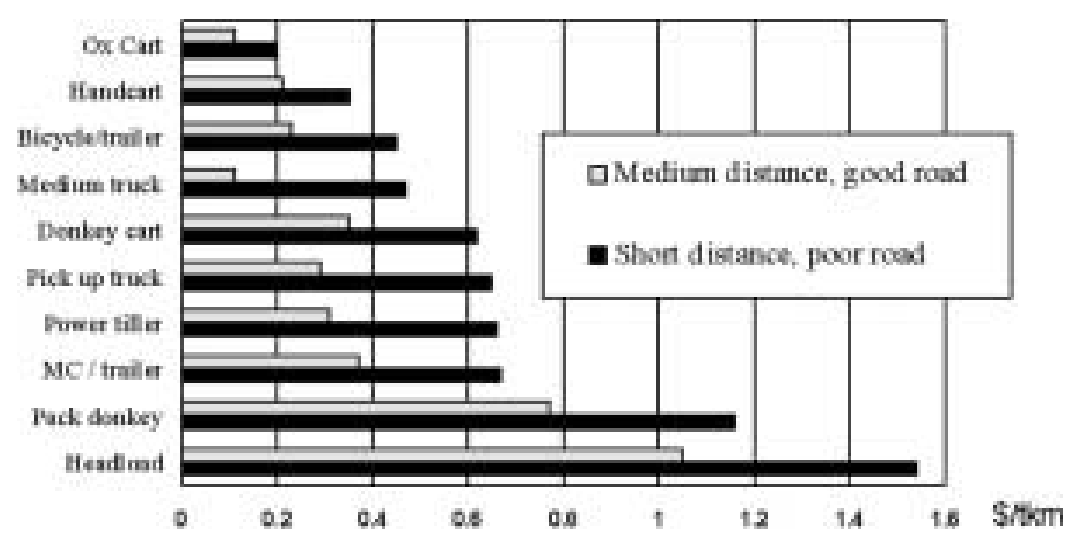

Figure 7. Typical transport costs in Sub-Saharan Africa. Source: Crossley and Ellis (1997)

The efficiency improvement in transport, which non-motorized means can generate, is a lesson to be learned by transport planners, especially in rural areas, where the export of agricultural goods is essential in the fight against poverty. Solutions are intermodal logistic transport systems, with the low-cost means taking care of the 'first mile's' journey from the field to the collection point, where the trucks pick up their loads.

In urban areas, especially in Asian cities, non-motorized means of transport have an important share in transporting goods and passengers. More often than not, transport planners educated in the North ignore these modes and simply forget to implement adequate facilities, such as walkways, footbridges, bicycle lanes or loading facilities at markets. This makes walking and cycling even more dangerous, cumbersome, time consuming and costly. As a matter of course, this will also have negative impacts on the use of public transport systems.

\section{Improved Land-use Planning}

The spatial development in industrialized countries can be characterized by a concentration in the cities, which took place during the industrialization phase, followed by a process of massive suburbanization after the establishment of the automobile as the main mode of transport. During this period, urban sprawl not only took place along the railway lines, but also the entire suburban area around conurbations was used for settlements. Cars allowed for a decentralization of urban functions, i.e. to live in the countryside in detached houses and to commute to the urban centre for work.

Urban sprawl produced spatial structures, which result in long commuting distances and developments that are less easy to accommodate public transport systems. Given the lower energy requirements of public transport, suburbia is a settlement structure that entails large-scale energy inefficiencies in transport. An international comparison of cities (Figure 8$)^{15}$ shows that a strong relationship exists between urban density and car use (mileage). Higher-density locations result in lower specific energy consumption in transport.

In many developing countries, the process of suburbanization is still in its early stages. Even so-called megacities, such as Cairo, Egypt, cover a surface that comprises only a small fraction compared with cities in industrialized countries, 
such as Los Angeles, CA, USA, even though both conurbations have about the same number of inhabitants. However, tremendous urban growth, reaching levels up to $10 \%$ annually, will lead to a rapid expansion of urban areas in most developing countries. Additionally, it can be expected that in the future income in developing cities will increase and similar processes of suburbanization can be expected in the South.

Since spatial developments are very difficult to reverse, it is advisable to influence urban sprawl before car-dependent settlement structures have developed. The target is to create urban regions amenable to public transport including a city of short travel distances. A number of urban and transport planning measures can be taken to achieve this goal. The most important ones are as follows:

- Establishment of a regional administrative (and, if possible, a political) entity that can coordinate regional planning in- and outside administrative city borders. Its main task is the design and strict control of regional land-use schemes.

- Set-up of regional development plans, using a concept of decentralized concentration, according to a system of corridors and points. The main points are formed by the central business district, urban sub-centres and satellite towns,

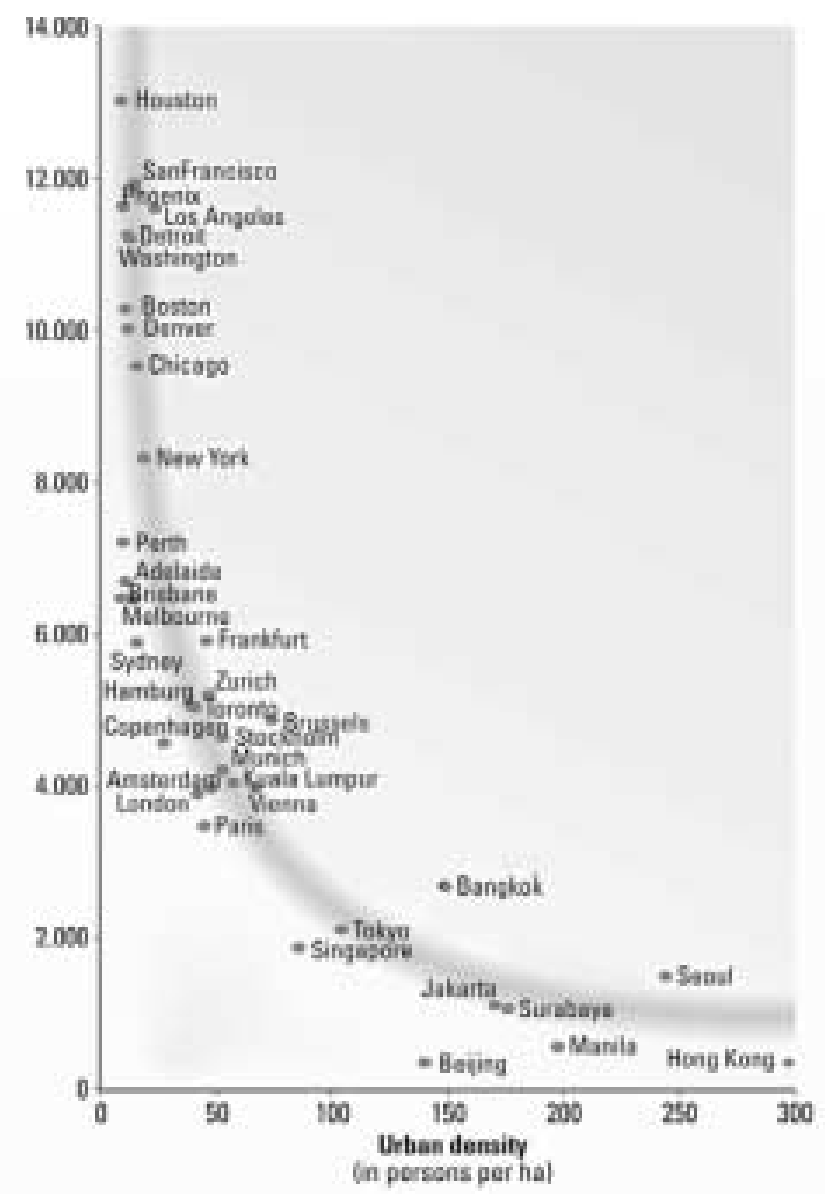

Figure 8. Annual car use per capita in 1990 and urban population density. Source: Kenworthy and Laube (1999) 


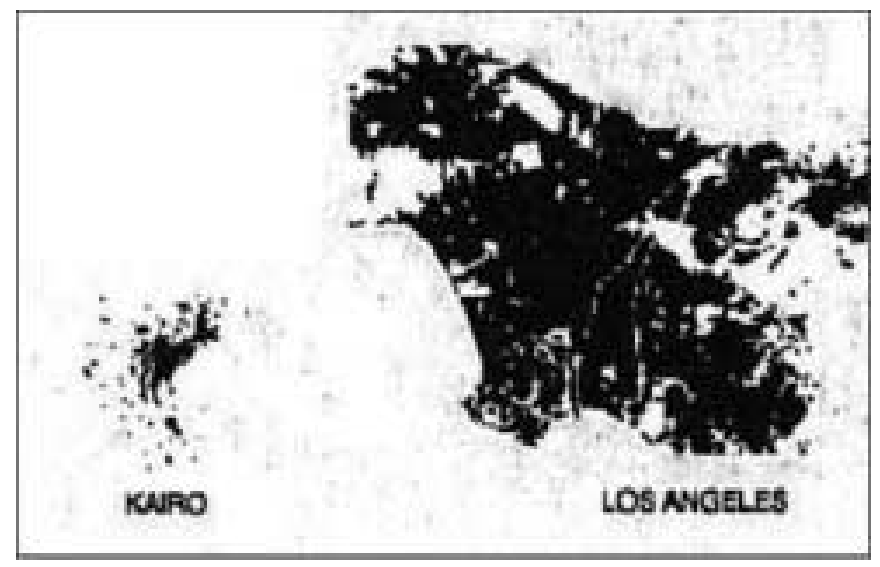

Figure 9. Similar population but a different size. Source: Sieverts (1998, p. 25)

with the corridors providing rapid mass transit systems connecting these centres.

- Settlement patterns are determined by mixed land use, with high urban densities around public transport stations and green belts forming barriers against urban sprawl. New major developments have to be located near existing highcapacity transit routes.

- Efficient public transport system and a traffic-management scheme are preconditions for the functioning of the city. An improvement of facilities for nonmotorized means of transport, such as walking and bicycling, is an important measure to make short trips more attractive.

- Economic incentives can be created to support the desired spatial development: taxes on land property, regional road pricing schemes and incentives for dense new developments. Subsidies for commuters are counterproductive.

The city of short distances is liveable, needs less transportation, produces less external effects and consumes less energy in transport. If early measures are taken, mistakes made in industrialized countries during the last decades can be avoided in developing cities.

\section{Financial Planning under Severe Budget Constraints}

Tight budget constraints and a constant lack of financial resources are salient features of developing countries. The fuel sector plays an important role in the economy of theses countries. In the transport sector more than $90 \%$ of transport modes use conventional fuels, much of which has to be imported. In low-income countries fuel imports often represent up to one-third of all foreign imports, causing large imbalances of trade. Thus, measures to increase energy efficiency in transport have strong impacts on the whole economy of developing countries.

In addition, the fuel sector can be an important source of revenue for the state. Taxes on fuel and energy may comprise up to $36 \%$ of all state taxes, or, in the reverse case, fuel subsidies may form a burden of up to $8 \%$ of the state budget. Worldwide, roads are financed by revenues from fuel taxation. In Africa, a fuel tax amounting to only US\$0.10 is sufficient to finance the adequate maintenance 
of the whole road network. However, an overview on the worldwide fuel taxation shows that many developing countries do not even generate this minimum amount and thus the road networks continue to deteriorate. ${ }^{16}$ This implies not only a depreciation of the state's largest assets, but also forces the individual user to pay for higher transport costs. Every euro saved on maintenance costs the user an additional 3, mainly through increased vehicle operating costs. Therefore, pricing and taxation issues for conventional fuels are of primary importance in developing countries.

Next to the issue of revenue collection, fuel taxes may serve as a means of environmental taxation. Economic instruments are most important to achieve improvements of energy efficiency in transport. The instruments may serve to reinforce or support the above-mentioned measures regarding the introduction of renewable energy sources, transportation demand management and transport avoiding land-use planning. Conventional taxes, such as fuel levy and vehicle licences fees, may focus on the reduction of environmental effects of transport, e.g. by favouring more energy-efficient engines. Transport-specific instruments, environmentally oriented vehicle taxation, road tolls and spatial/temporal differentiated road pricing systems may serve as efficient tools to change regional transport patterns towards a higher energy efficiency.

The potential for changing behaviour should not be underestimated. Driver training for an economically and ecologically sound driving style is a cheap method to save fuel and money, as well as contributing to road safety and a reduction in greenhouse gas emissions. The average reduction of fuel consumption amounts to $10 \%$. Pay back periods of the training lessons are reasonably short. Nevertheless, the development of the market eco-driving is slow, at least in Europe.

\section{Conclusions for International Development Cooperation}

The cheapest and most promising means to reduce energy use in transport is through the improvement of energy efficiency, either by technical improvements or by modern urban planning approaches. This fact should be borne in mind by every decision maker interested in reducing environmental damage, human disease and societal costs caused by the transport sector. But if serious predictions come true (e.g. the oil price remains on high levels between 40 and 60 US\$/ barrel), or if further political targets are implemented (e.g. the European Directive on biofuels), renewable energies such as ethanol and biodiesel will play a more important role in transport. However, in each case, energy efficiency should be given special attention.

Currently, a large number of developing countries are fascinated by biofuels because they could have positive impacts on their economies and social situations. In industrialized countries the production capacities of fossil fuels as well as potentials of renewables can only satisfy a small share of the energy demand in transport. Therefore, developing countries expect options to produce biofuels for export. Since farmers have to produce and sell plants, this might have positive effects on rural development, where poverty prevails. However, social and economic conditions are sufficiently complex that no general prediction on sustainability can be made. Here, the key question is: what are the market conditions for the farmers? Can they partake in the creation of value or do they only produce for very small income? 
Besides the use of renewables, there are a number of strategies to reduce energy consumption and thus improve energy efficiency in transport. Improved technical inspection and maintenance of vehicles can improve energy efficiency significantly. Other strategies comprise measures from the 'traditional' repertoire of transport planners. Especially in the rapid growing cities in developing countries, large-scale impacts can be expected. Modal shift towards more energy-efficient means of transport-or the retention of the existing high share of people walking, cycling or using transit-and the planning of cities with short distances are two issues that will be of crucial importance in order to secure liveable cities and reduce GHG emissions.

An important aspect is the expected urban sprawl of developing cities. If planning mistakes from the North, such as the establishment of car-dependent settlement structures, can be avoided in the South, a planning approach that integrates transport and regional planning has to be taken. Up to now, neither donors nor decision-makers in developing cities seem to be aware of the future problems and have yet to take appropriate measures.

To date, emission reductions from the transport sector have not played a significant role in the Kyoto mechanisms, such as the Clean Development Mechanism or Joint Implementation. Only very few transport-related projects have been registered under these mechanisms. Action is urgently needed.

\section{Notes}

1. See http://www.iea.org

2. A two seater, with very little space for baggage and a slow speed.

3. For example, a VW Lupo 3L TDI.

4. For example, a Daihatsu Cuore and an Opel Corsa Eco.

5. The Toyota Prius, which can be used as a family vehicle, consumes 4.3 litres and is, especially in urban areas, without competitors with respect to noise and emissions (due to the high efficiency of electric engines in urban transport).

6. GTZ (2003b), Module 5a: Air Quality Management, p. 28.

7. GTZ (2003b), Module 4b: Inspection \& Maintenance and Roadworthiness.

8. GTZ (2003b), Module 4c: Two- and Three-wheelers.

9. Approximately $425 \mathrm{EJ}$ in 2002.

10. Most of the information is given in GTZ (2003b), Module 4a: Cleaner Fuels and Vehicle Technology.

11. National Biodiesel Board, USA. Available at: http://www.biodiesel.org

12. Data used are from Verkehr in Zahlen 2002/03.

13. For more information on bus rapid transit, see GTZ (2003b), Module 3b.

14. For walking travel time, valuations are essential in order to estimate transport costs. Assuming an average load of $25 \mathrm{~kg}$ per person and a speed of $3 \mathrm{~km} / \mathrm{h}$, the transport of 1 tonne-km requires 27 hours of travel time. Forty return trips covering $80 \mathrm{~km}$ have to be walked.

15. Kenworthy and Laube (1999), cited in GTZ (2003b), Module 2a: Land-use Planning.

16. GTZ (2003a).

\section{References}

Bundesministerium für wirtschaftliche Zusammenarbeit und Entwicklung (2003) Materialien: Transport und Verkehr - Zukunftsfähige Mobilität für eine gerechte und nachhaltige Entwicklung (Bonn: BMZ).

Crossley, P. and Ellis, S. (1997) A Handbook of Rural Transport Vehicles in Developing Countries (Bedford: Silsoe College, TRL).

EIA (1999) Annual Energy Outlook 2000 - With Projections to 2020 (Washington, DC: US Department of Energy).

Goldemberg, J., Coelho, S. T., Nastari, P. M. and Lucon, O. (2003) Ethanol learning curve - the Brazilian experience. Biomass and Bioenergy, 26(3), pp. 301-304. 
GTZ (2003a) International Fuel Prices, 3rd Edn (Eschborn: GTZ). Available at: http://worldbank.org/ transport or http:/ / zietlow. com/docs/engdocs.htm

GTZ (2003b) Sustainable Transport: A Sourcebook for Policy Makers in Developing Cities (Eschborn: GTZ). Available at: http://www.sutp.org/docs/sourcebook/sourcebook.aspx

GTZ (2004) Transport in Developing Countries: Renewable Energy or Energy Reduction? Reader prepared for the Side Event at the Renewables 2004 Conference, ed. N. Sieber (Eschborn: GTZ).

IEA (2004) Biofuels for Transport - An International Perspective (Paris: IEA).

Ingram, G. K. and Liu, Z. (1999) Determinants of Motorization and Road Provision. Policy Research Working Paper No. 2042 (New York, NY: World Bank).

Johansson, T., McCormick, K., Neij, L. and Turkenburg, W. (2004) The potentials of renewable energy. Thematic Background paper, in: International Conference for Renewable Energies, Bonn, Germany, 2004.

Kenworthy, J. and Laube, F. (1999) An International Sourcebook of Automobile Dependence in Cities, 1960 1990, updated edition (Boulder, CO: University Press of Cororado).

McClintock, H. (2001) Comprehensive Transportation Planning Bibliography (Nottingham: Institute of Urban Planning, University of Nottingham). Available at: http://www.nottingham.ac.uk/sbe/ planbiblios/bibs

Newman, P. and Kennworthy, J. (1999) Sustainability and Cities; Overcoming Automobile Dependency (Washington, DC: Island).

Quirin, M., Gärtner, S. O., Pehnt, M. and Reinhardt, G. A. (2004) $\mathrm{CO}_{2}$ Mitigation through Biofuels in the Transport Sector-Status and Perspectives (Heidelberg: Institute for Energy and Environmental Research).

Sieverts, T. (1998) Zwischenstadt zwischen Ort und Welt, Raum und Zeit, Stadt und Land, BauweltFundamente (Braunschweig; Wiesbaden), 118.

Verkehr in Zahlen (2002/2003) Hrsg (Bonn: Bundesministerium für Verkehr).

Weber, M. (2004) Bioethanol - herstellung in Deutschland und Brasilien. Ein technischer, ökonomischer und ökologischer Vergleich Master's thesis zur Erlangung des akademischen Grades Master of Science 'Energy Conversion and Management'. University of Applied Sciences Offenburg.

Wright, L. (2004) The limits of technology: achieving transport efficiency in developing nations, in GTZ (2004) Transport in Developing Countries: Renewable Energy or Energy Reduction? Reader prepared for the Side Event at the Renewables 2004 Conference, ed. N. Sieber (Eschborn: GTZ).

WTRG (2005) Brent Spot Prices (London: WTRG Economics). Available at: http://www.wtrg.com (accessed on 25 January 2005). 